J. Clin. Chem. Clin. Biochem.

Vol. 19, 1981, pp. $931-941$

\title{
A Comparative Study of the Activity of Lysosomal and Main Metabolic Pathway Enzymes in Tissue Biopsies and Cultured Fibroblasts from Dupuytren's Disease and Palmar Fascia
}

On the pathobiochemistry of connective tissue proliferation, I.

By A. Delbrück, E. Reimers ${ }^{1}$ ) and I. Schönborn ${ }^{1}$ )

(Received July 2, 1980/January 19, 1981)

Respectfully dedicated to Prof. Dr. Fritz Hartmann, Hannover, on the occasion of his 60 th birthday

Summary: Activities of ten main metabolic pathway enzymes and seven lysosomal enzymes were determined in specimens from human normal palmar fascia and Dupuytren's contracture. The activities of the enzymes tested are 2-3 times higher in fresh specimens of Dupuytren's contracture. There are no differences in the activity distribution patterns of both these specimens, or in the absolute activities calculated in relation of the glyceraldehyde-3-phosphate dehydrogenase activities. With the exception of adenylate kinase and pyruvate kinase, the activities of main metabolic pathway enzymes based on the DNA content showed significantly lower activities in Dupuytren's contracture tissue than in palmar fascia. Lysosomal enzymes exhibit no significant differences of activity in the respective specimens. However, the lysosomal enzyme activities of cultured fibroblasts are lower than the corresponding activities from tissue specimens. The enzyme activities per DNA content in cultured fibroblasts are 10-50 times higher than in tissue specimens. The enzyme activities in cultured fibroblasts decrease with age or density of the cells in culture. The increased metabolic activity of the diseased tissues in Dupuytren's contracture is due to the higher cell content of the afflicted portions of the tissue, but individual enzymes show no qualitative changes in activity and there are no increases of enzyme activity per cell (DNA).

Eine vergleichende Untersuchung über die Aktivitäten lysosomaler und Hauptketten-Enzyme in Biopsiematerial und Fibroblasten in der Gewebekultur von Palmarfascie und Dupuytren'schem Kontrakturgewebe

\section{Zur Pathobiochemie der Bindegewebsproliferation, 1. Mitteilung}

Zusammenfassung: Die Aktivitäten von 10 Hauptkettenenzymen und sieben lysosomalen Enzymen wurden in Gewebsproben von normalen menschlichen Palmaraponeurosen und von Dupuytren'scher Kontraktur bestimmt. Die ermittelten Enzymaktivitäten lagen in den frischen Proben der Dupuytren'schen Kontraktur 2-3 mal höher als in Gewebe von Palmarfaszie. Differenzen in der relativen Enzymverteilung zwischen den Proben von Dupuytren'scher Kontraktur und Pälmarfaszie konnten nicht festgestellt werden. Ebenfalls fanden sich keine signifikanten Unterschiede beim Bezug der Enzymaktivitäten auf dịe Glycerinaldehydphosphatdehydrogenase als Bezugssystem. Die Aktivitäten von Hauptkettenenzymen im Bezug auf den DNA-Gehalt der Gewebsproben waren im Dupuytren'schen Kontrakturgewebe signifikant niedriger als in dem Vergleichsmaterial der Palmaraponeurose mit der Ausnahme von Adenylatkinase und Pyruvatkinase. Lysosomale Enzyme zeigten keine signifikanten Unterschiede in ihrer Aktivität in den entsprechenden Geweben. In Fibroblasten, welche aus den entsprechenden Gewebsproben gezüchtet wurden, waren die Aktịvităten lysosomaler Enzyme vergleichsweise niedriger als in den zugehörigen Gewebsproben. Die Aktivitäten in den Fibroblasten im Bezug auf den DNA-Gehalt fanden sich 10-50 mal höher als in den entsprechenden Gewebsproben. Die Enzymaktivitäten in Fibroblasten nehmen mit zunehmender Dichte und Alter der Kultur ab. Die erhöhte metabolische Aktivität der betroffenen Gewebspartien bei der Dupuytren'schen Kontraktur muß auf den erhöhten Zellgehalt der Gewebe zurückgeführt werden und geht nicht mit qualitativen Veränderungen der Aktivitäten einzelner Enzyme oder êiner Zunahme der Enzymaktivitäten in den Zellen einher.

\section{Introduction}

Malfunction of tissue repair plays a major role when considering pathological states of connective tissues. In addition to those connective tissue diseases which are characterized by lack of defence or repair reactions, other cases are characterized by uncontrolled tissue proliferation leading to severe destruction and malfunction of connective tissue structures. The progressive con-

1) This publication contains data from the Doctoral Thesis of E. Reimers and I. Schönborn. 
tracture of palmar and plantar fascia first described in 1614 by E. Plater (1) and investigated in 1832 by Dupuytren (2) is morphologically characterized by heavy cell proliferation and destruction as well as rebuilding of fibre proteins (3). In contrast to the large number of publications on the morphological changes of the tissue structure in Dupuytren disease, only a few papers have been published on the pathobiochemistry of this disorder. They indicate an increased collagen and glycosaminoglycan content and metabolism of the afflicted tissue portions (4-8).

Data from an earlier study performed in our laboratory on connective tissue demonstrated an increase in the activity of main metabolic pathway enzymes in Dupuytren tissue (11). The enzyme activity pattern showed a similar distribution to that found in other connective tissues, with relatively high activities of phosphate transferases. During the course of our investigation, Hoopes et al. published data on enzymes of glucose metabolism in Dupuytren contracture and the adjacent skin showing elevated activities in both these tissues (12). The goal of the present study was the confirmation of our earlier results on a larger group of patients with Dupuytren contracture. Furthermore a comparative study of enzyme activities in cultured fibroblasts grown from normal palmar aponeurosis and Dupuytren contracture should reveal basic data for the interpretation of in-vitro experiments on the pathobiochemistry of connective tissue proliferation.

The enzymes ${ }^{2}$ ) chosen for activity determination were lactate dehydrogenase representing glycolysis, glyceraldehyde-3-phosphate dehydrogenase for the EmbdenMeyerhof pathway, adenylate kinase, pyruvate kinase and 3-phosphoglycerate kinase as phosphate transfer enzymes, malate dehydrogenase and isocitrate dehydrogenase for the Krebs cycle, glucose-6-phosphate dehydrogenase for the hexose monophosphate shunt, glutamateoxalacetate transaminase, glutamate-pyruvate transaminase and glutamate dehydrogenase for amino acid metabolism, collagen peptidase and cathepsin B 1 representing collagen breakdown and $\beta$-glucuronidase, $\alpha$-N-acetyl-glucosaminidase, $\alpha$ - $L$-fucosidase, arylsulfatase for carbohydrate decomposition, and acid phosphatase.

\section{Material and Methods}

\section{Tissue specimens}

Tissue specimens were taken during surgery from patients aged 40-70 years suffering from Dupuytren's contracture of the hand. Normal aponeurosis specimens are obtained by autopsy within $24 \mathrm{~h}$ post mortem. The specimens were freed from adjacent tissue and blood, cut into small pieces and homogenized with an ultraturrax-homogenizer (Janke and Kunkel, Stauffen, Germany) at $4^{\circ} \mathrm{C}$ in $0.15 \mathrm{~mol} / 1 \mathrm{KCl}, 1 \mathrm{ml} / 1$ Trition X 100 ten times for 15 minutes, followed by 30 minutes intermission to avoid an increase in temperature. The homogenate was extracted for 60 minutes by stirring at $+4^{\circ} \mathrm{C}$ followed by a second homogenisation as above. The extract was cleared by centrifugation at $100000 \mathrm{~g}$ for 30 minutes (Superspeed 50, MSE Ltd., London
SW 1, England). The pellet was extracted by acetone for dry weight estimation and DNA assay.

The biopsy specimens were macroscopically examined and the nodular portions selected for the extraction and enzyme activity determinations (in the following referred to as Dupuytren's contracture).

One part of these specimens underwent microscopic examination and could be characterized as cell-rich proliferating tissue (proliferating stage). From suitable specimens thin unsuspected portions of biopsies were collected. They showed microscopically no or only slight proliferation (thin portion of Dupuytren's contracturè).

The reference group (palmar fascia) exhibited a normal microscopical tissue structure.

\section{Enzyme activity determinations}

Enzyme activity determination was performed in triethanolamine buffer $50 \mathrm{mmol} / \mathrm{l}$ and ethylenediamine tetraacetate (disodium salt) $3 \mathrm{mmol} / \mathrm{l}, \mathrm{pH} 7.5$ at $25^{\circ} \mathrm{C}$ and measured at the appropriate wavelength in the Photometer Eppendorf (Eppendorf Gerätebau GmbH, Hamburg, Germany) or the Beckman 25 Spectrophotometer (Beckman Instruments $\mathrm{GmbH}$, Munich, Germany) if not otherwise stated.

The substrate concentrations in the tests were:

\section{Lactate dehydrogenase}

NADH $0.1 \mathrm{mmol} / \mathrm{l}_{\mathrm{j}} \mathrm{MgCl}_{2} 5 \mathrm{mmol} / \mathrm{l}$, pyruvate $1.25 \mathrm{mmol} / \mathrm{l}$

\section{Glyceraldehyde-3-phosphate dehydrogenase}

NADH $0.1 \mathrm{mmol} / \mathrm{l}$, glutathione (GSH) $2.5 \mathrm{mmol} / \mathrm{l}, \mathrm{MgSO}_{4}$ $10 \mathrm{mmol} / 1$, 3-phosphoglycerate $3 \mathrm{mmol} / 1$, phosphoglycerate kinase $4000 \mathrm{U} / \mathrm{l}$, ATP $5 \mathrm{mmol} / 1$

2) Enzymes

Adenylate kinase (ATP: AMP phosphotransferase, EC 2.7.4.3)

Acid phosphatase (Orthophosphoric-monoesterphospho-

hydrolase, EC 3.1.3.2)

Arylsulfatase (EC 3.1.6.1)

Cathepsin B1 (EC 3.4.22.2)

Collagen peptidase (EC 3.4.4.-)

$\alpha-L$-Fucosidase (EC 3.2.1.51)

Glyceraldehyde-3-phosphate dehydrogenase

(D-Glyceraldehyde-3-phosphate: NAD oxidoreductase phosphorylating, EC 1.2.1.12)

$\alpha$-N-Acetyl-glucosaminidase

Glutamate dehydrogenase ( $L$-Glutamate: NAD (P)oxidoreductase (deaminating), EC 1.4.1.3)

$\beta$-Glucuronidase ( $\beta$ - $D$-Glucuronide-glucuronohydrolase, EC 3.2.1.31)

Glutamate-oxalacetate transaminase ( $L$-Aspartate:

2-oxoglutarate aminotransferase, EC 2.6.1.1)

Glutamate-pyruvate transaminase ( $L$-Alanine:

2-oxoglutarate aminotransferase, EC 2.6.1.2)

Glucose-6-phosphate dehydrogenase (D-Glucose-6-phosphate: NADP oxidoreductase EC 1.1.1.49)

Isocitrate dehydrogenase (threo-D-Isocitrate: NADP oxidoreductase (decarboxylating) EC 1.1.1.42)

Lactate dehydrogenase ( $L$-Lactate: NAD oxidoreductase, EC 1.1.1.27)

Malate dehydrogenase ( $L$-Malate: NAD oxidoreductase, EC 1.1.1.37)

Pyruvate kinase (ATP: pyruvate phosphotransferase, EC 2.7.1.40)

3-Phosphoglycerate kinase (ATP: 3-phospho-D-gly cerate 1-phosphotransferase EC 2.7.2.3) 


\section{Pyruvate kinase}

NADH $0.25 \mathrm{mmol} / 1$, phosphoenolpyruvate $2.5 \mathrm{mmol} / 1, \mathrm{MgSO}_{4}$ $10 \mathrm{mmol} / \mathrm{l}, \mathrm{KCl} 100 \mathrm{mmol} / \mathrm{l}$, lactate dehydrogenase $7200 \mathrm{U} / 1$, ADP $1.25 \mathrm{mmol} / 1$

\section{Adenylate kinase}

$\mathrm{NADH} 0.1 \mathrm{mmol} / 1, \mathrm{MgSO}_{4} 50 \mathrm{mmol} / \mathrm{l}, \mathrm{KCl} 50 \mathrm{mmol} / 1$, phosphoenolpyruvate $1.25 \mathrm{mmol} / \mathrm{l}$, lactate dehydrogenase $18000 \mathrm{U} / \mathrm{l}$, pyruvate kinase $6000 \mathrm{U} / \mathrm{l}$, ATP $1 \mathrm{mmol} / 1$, AMP $1 \mathrm{mmol} / 1$

\section{Malate dehydrogenase}

NADH $0.2 \mathrm{mmol} / 1$, oxalacetate $0.2 \mathrm{mmol} / 1$

\section{Glucose-6-phosphate dehydrogenase}

NADH $0.5 \mathrm{mmol} / 1$, glucose-6-phosphate $2.4 \mathrm{mmol} / 1$

\section{Isocitrate dehydrogenase}

NADP $0.3 \mathrm{mmol} / \mathrm{l}, \mathrm{MnCl}_{2} 5 \mathrm{mmol} / 1$, isocitrate $1.9 \mathrm{mmol} / \mathrm{l}$

\section{Glutamate-oxalacetate transaminase}

NADH $0.25 \mathrm{mmol} / 1,2-0 x$ oglutarate $9 \mathrm{mmol} / \mathrm{l}, \mathrm{KCl} 30 \mathrm{mmol} / \mathrm{l}$, malate dehydrogenase $22000 \mathrm{U} / 1, L$-aspartate $0.1 \mathrm{~mol} / 1$, phosphate buffer $50 \mathrm{mmol} / 1, \mathrm{pH} 7.5$

\section{Glutamate-pyruvate transaminase}

NADH $0.3 \mathrm{mmol} / 1,2$-oxoglutarate $11.25 \mathrm{mmol} / \mathrm{l}$, lactate dehydrogenase $9000 \mathrm{U} / 1, L$-alanine $0.3 \mathrm{~mol} / 1$

\section{Glutamate dehydrogenase}

ADP $1.0 \mathrm{mmol} / 1$, NADH $0.15 \mathrm{mmol} / \mathrm{l}$, ammonium sulphate $80 \mathrm{mmol} / \mathrm{l}, 2$-oxoglutarate $8 \mathrm{mmol} / \mathrm{l}$

\section{3-Phosphoglycerate kinase}

NADH $0.1 \mathrm{mmol} / 1$, EDTA $2.6 \mathrm{mmol} / 1$, gly cerate-3-phosphate $6.0 \mathrm{mmol} / 1, \mathrm{MgSO}_{4} 7.5 \mathrm{mmol} / \mathrm{l}$, glutathione (GSH) $2.5 \mathrm{mmol} / \mathrm{l}$, glyceraldehyde-3-phosphate dehydrogenase 7000 U/1, ATP $2.5 \mathrm{mmol} / \mathrm{l}$

The lysosomal enzyme activity determinations were carried out as follows:

\section{Arylsulfatase}

Sodium acetate buffer $72 \mathrm{mmol} / 1, \mathrm{pH} 6.2 ; 4$-nitrophenyl-hydrogensulphate potassium salt $10 \mathrm{mmol} / 1$, incubation for $60 \mathrm{~min}$ at $37^{\circ} \mathrm{C}$. Reaction stopped by addition of $\mathrm{NaOH}$ final concentration 1.33 mmol/l. Photometer Eppendorf 405 nm ((13), modified)

\section{B-Glucuronidase}

Sodium acetate buffer $96 \mathrm{mmol} / 1$, nitrophenyl- $\beta$ - $D$-glucuronide $10 \mathrm{mmol} / 1$, pH 4.8 , incubation for $60 \mathrm{~min}$ at $37^{\circ} \mathrm{C}$. Reaction stopped by addition of gly cine carbonate final concentration $133 \mathrm{mmol} / 1, \mathrm{pH} 10$. Photometer Eppendorf $405 \mathrm{~nm}$

\section{$\alpha-N$-Acetyl-glucosaminidase}

Sodium citrate buffer $39 \mathrm{mmol} / \mathrm{l}, \mathrm{pH} 4.2, p$-nitrophenyl-2acetamido-2-deoxy- $\alpha-D$-glucopyranoside $7.98 \mathrm{mmol} / 1$, incubation for $60 \mathrm{~min}$ at $37^{\circ} \mathrm{C}$. Reaction stopped by addition of glycine $\mathrm{NaOH}$ buffer, final concentration $320 \mathrm{mmol} / \mathrm{l}, \mathrm{pH} 10.4$. Photometer Eppendorf 405 nm (15)

\section{$\alpha-L-F u c o s i d a s e$}

Citrate phosphate buffer $53 \mathrm{mmol} / 1, \mathrm{pH} 6.1, p$-nitrophenyl-Dfucoside $0.5 \mathrm{mmol} / 1$, incubation for $60 \mathrm{~min}$ at $37^{\circ} \mathrm{C}$. Reaction stopped by addition of hydrogen carbonate buffer final concentration $100 \mathrm{mmol} / \mathrm{l}$, pH 10.6. Photometer Eppendorf $405 \mathrm{~nm}(16)$.

\section{Collagen peptidase}

Tris-HCl buffer $120 \mathrm{mmol} / \mathrm{l}$, pH 7.2, 4-phenylazobenzyl-oxycarbonyl- $L$-proly $1-L$-leucyl-gly cy $1-L$-proly $1-D$-arginine-dihydrate
$0.41 \mu \mathrm{mol} / \mathrm{l}$, incubation $60 \mathrm{~min}$ at $37 .-\mathrm{C}$. Reaction stopped by addition of citric acid, final concentration $30 \mathrm{mmol} / \mathrm{l}$, extraction of the reaction product with benzene. Photometer Eppendorf $334 \mathrm{~nm}(17)$

\section{Cathepsin B I}

Hydrogencarbonate/carbonate buffer $190 \mathrm{mmol} / \mathrm{l}, \mathrm{pH}$ 6.0, Ethylenediaminetetraacetate disodium salt $0.95 \mathrm{mmol} / 1$, cysteine hydrochloride $1.9 \mathrm{mmol} / \mathrm{l}, \alpha$-benzoy $1-D, L$-arginine-2-naph thylamide $2.19 \mathrm{mmol} / 1$ in dimethylsulfoxide, incubation for $10 \mathrm{~min}$ at $25^{\circ} \mathrm{C}$. Photometer Eppendorf $340 \mathrm{~nm}(18,19)$

\section{Acid phosphatase}

Citrate buffer $40 \mathrm{mmol} / \mathrm{l}, \mathrm{pH} 4.8$; Na-p-nitrophenylphosphate $4.6 \mathrm{mmol} / \mathrm{l}, 37^{\circ} \mathrm{C}$. Photometer Eppendorf $405 \mathrm{~nm}$ (20).

Enzyme activities are expressed in $U$ ( $\mu \mathrm{mol}$ substrate turnover per minute under the given conditions).

Protein assay: was performed according to Weichselbaum (21) in extracts of biopsy specimens; and by the method of Lowry et al. (22) for autopsy and fibroblast extracts.

Blood contamination: was calculated by haemoglobin determination according to Crosby \& Furth (23).

DNA determination: modified according to Burton (24). Following enzymatic proteolysis by papain (25), precipitation of DNA by $\mathrm{HClO}_{4}$ (final concentration $1 \mathrm{~mol} / \mathrm{l}$ ) and centrifugation at $2400 \mathrm{~g} 15$ minutes. Hydrolysis of the pellet in $0.5 \mathrm{~mol} / \mathrm{l}$ $\mathrm{HCl}$ at $70^{\circ} \mathrm{C}$ for 20 minutes, photometry with diphenylamine reagent at $600 \mathrm{~nm}$ Beckman Spectrophotometer 25 .

Hydroxyproline assay: according to Stegemann (26).

Cell culture conditions: minimum essential medium with Earl's salt and $10 \%$ fetal calf serum at $37{ }^{\circ} \mathrm{C} ; 95 \%$ air $/ 5 \% \mathrm{CO}_{2}(25)$.

Cell extract: cells are freed from culture flasks by pronase, washed with isotonic sodium chloride and resuspended in $0.15 \mathrm{~mol} / 1 \mathrm{KCl}$ containing $0.1 \mathrm{ml} / 1$ Triton $X 100$ (27) and $2.5 \mathrm{mmol} / \mathrm{l}$ ethylenediaminetetraacetate disodium salt. An aliquot of the suspension was taken for cell counting in the TOA cell counter (Colora Meßtechnik Lorch, Germany). The remaining suspension was treated for 10 minutes by ultrasonic irradiation, centrifuged for 20 minutes at $100000 \mathrm{~g}$. The supernatant was used for enzyme activity determination and protein assay.

\section{Results}

Enzyme activity determinations in strong tissues such as palmar fascia depend as much on the method used to disrupt the tissue structure and to extract the homogenates as on the test conditions chosen for the activity assays. The methods applied in this study include the addition of triton X 100 to the extraction medium which resulted in extraction rates five times higher for lysosomal enzymes, while no effect in the yield of main metabolic enzymes could be observed. Triton X 100 did not interfere with the activity estimation of these enzymes. Repeated breakdown and extraction of the tissue specimens leads to a gain of less than $10 \%$ of the enzyme activities present in the first extract; only the first extract was taken for enzyme determinations in this study. The extraction of cultured fibroblasts is practically complete; after extraction, cell residues show no measurable activity of main metabolic pathway enzymes or lysosomal enzymes.

For interpretation of the data on the enzyme activities in the different specimens, wet weight, dry weight, DNA 
and hydroxyproline content and the amount of extractable protein were determined (tab. 1A). Dry weight and hydroxyproline content do not differ between Dupuytren's contracture and palmar fascia. The extracted protein values of Dupuytren's contractures are found to be twice as high as those of palmar fascia and the DNA content about four times higher in Dupuytren's contracture than in palmar fascia. The respective data for the thin portion of Dupuytren tissue are between those for Dupuytren's contracture and palmar fascia values. The statistical significance of these findings is listed in table 1B. Enzyme activity represented by the activity of glyceraldehyde-3-phosphate dehydrogenase follows the DNA content of the specimens (fig. 1) in the palmar fascia and Dupuytren's contracture. The macroscopically classified nodular portions (Dupuytren's contracture, fig. 1) and the tissue specimens which were histologically classified as proliferating state of Dupuytren's contracture showed no significant differences in dry weight, extractable protein, hydroxyproline or DNA content. The results of the enzyme activity determinations are summarized in figure 2 and tables $2 \mathrm{~A}$ and $2 \mathrm{~B}$. The activity distribution patterns are characterized by high activities of lactate dehydrogenase, malate dehydrogenase and phosphotransferases while the activities of the transaminases, glutamate dehydrogenase and glucose-6-

Tab. 1. Deoxyribonucleic acid content, dry weight, extracted protein and hydroxyproline content of palmar fascia and Dupuytren's contracture (subgroups). A: content per kg wet weight. B: significance level of differences between the specimen groups.

\begin{tabular}{|c|c|c|c|c|c|c|c|c|c|c|}
\hline \multirow[t]{2}{*}{$\mathbf{A}$} & \multicolumn{2}{|c|}{ Palmar fascia } & \multicolumn{3}{|c|}{$\begin{array}{l}\text { Nodular portion } \\
\text { Dupuytren's contracture }\end{array}$} & \multicolumn{3}{|c|}{$\begin{array}{l}\text { Thin portion } \\
\text { Dupuytren's contracture }\end{array}$} & \multicolumn{2}{|c|}{ Proliferating stage } \\
\hline & $\mathrm{n}$ & $\bar{x} \pm s \bar{x}$ & $\mathrm{n}$ & \multicolumn{2}{|c|}{$\bar{x} \pm s_{\bar{x}}$} & $\mathbf{n}$ & \multicolumn{2}{|c|}{$\overline{\mathbf{x}} \pm s \overline{\mathbf{x}}$} & $\mathrm{n}$ & $\bar{x} \pm s \bar{x}$ \\
\hline (g/kg wet weight) & 13 & $0.2 \pm 0.02$ & 28 & \multicolumn{2}{|c|}{$0.62 \pm 0.05$} & 12 & \multicolumn{2}{|c|}{$0.39 \pm 0.05$} & 11 & $0.54 \pm 0.08$ \\
\hline $\begin{array}{l}\text { Dry weight } \\
\text { (kg/kg wet weight) }\end{array}$ & 15 & $0.21 \pm 0.03$ & 30 & \multicolumn{2}{|c|}{$0.19 \pm 0.009$} & 11 & \multicolumn{2}{|c|}{$0.17 \pm 0.01$} & 11 & $0.21 \pm 0.03$ \\
\hline $\begin{array}{l}\text { Extracted protein } \\
\text { (g/kg wet weight) }\end{array}$ & 17 & $1.34 \pm 0.1$ & 27 & \multicolumn{2}{|c|}{$2.15 \pm 0.16$} & 13 & \multicolumn{2}{|c|}{$1.97 \pm 0.2$} & 12 & $2.0 \pm 0.12$ \\
\hline $\begin{array}{l}\text { Hydroxyproline } \\
\text { (g/kg wet weight) }\end{array}$ & 13 & $24.7 \pm 2.2$ & 27 & 23.9 & \pm 1.2 & 10 & 21.3 & \pm 1.8 & 10 & $22.5 \pm 2$ \\
\hline B & \multicolumn{2}{|l|}{$\mathrm{p}$} & \multicolumn{3}{|l|}{$\mathrm{p}$} & \multicolumn{3}{|l|}{ p } & \multicolumn{2}{|l|}{$\mathrm{p}$} \\
\hline Palmar fascia & \multicolumn{2}{|c|}{$\begin{array}{l}\text { DNA } \\
\text { Dry weight }\end{array}$} & \multicolumn{3}{|c|}{$\begin{array}{l}0.000 \\
0.67\end{array}$} & \multicolumn{3}{|c|}{$\begin{array}{l}0.001 \\
0.19\end{array}$} & \multicolumn{2}{|l|}{$\begin{array}{l}0.01 \\
0.34\end{array}$} \\
\hline $\begin{array}{l}\text { Nodular portion } \\
\text { Dupuytren's contracture }\end{array}$ & \multicolumn{2}{|c|}{$\begin{array}{l}0.000 \\
0.63\end{array}$} & \multicolumn{3}{|c|}{$\begin{array}{l}\text { Protein } \\
\text { Hydroxy- } \\
\text { proline }\end{array}$} & \multicolumn{3}{|c|}{$\begin{array}{l}0.003 \\
0.28\end{array}$} & \multicolumn{2}{|c|}{$\begin{array}{l}0.53 \\
0.50\end{array}$} \\
\hline $\begin{array}{l}\text { Thin portion } \\
\text { Dupuytren's contracture }\end{array}$ & \multicolumn{2}{|c|}{$\begin{array}{l}0.002 \\
0.67\end{array}$} & \multicolumn{3}{|c|}{$\begin{array}{l}0.49 \\
0.24\end{array}$} & \multicolumn{3}{|c|}{$\begin{array}{l}\text { Protein } \\
\text { Hydroxy- } \\
\text { proline }\end{array}$} & \multicolumn{2}{|c|}{$\begin{array}{l}0.11 \\
0.41\end{array}$} \\
\hline Proliferating & \multicolumn{2}{|c|}{$\begin{array}{l}0.000 \\
0.81\end{array}$} & \multicolumn{3}{|c|}{$\begin{array}{l}0.41 \\
0.85\end{array}$} & \multicolumn{3}{|c|}{$\begin{array}{l}0.96 \\
0.49\end{array}$} & \multicolumn{2}{|c|}{$\begin{array}{l}\text { Protein } \\
\text { Hydroxyproline }\end{array}$} \\
\hline
\end{tabular}

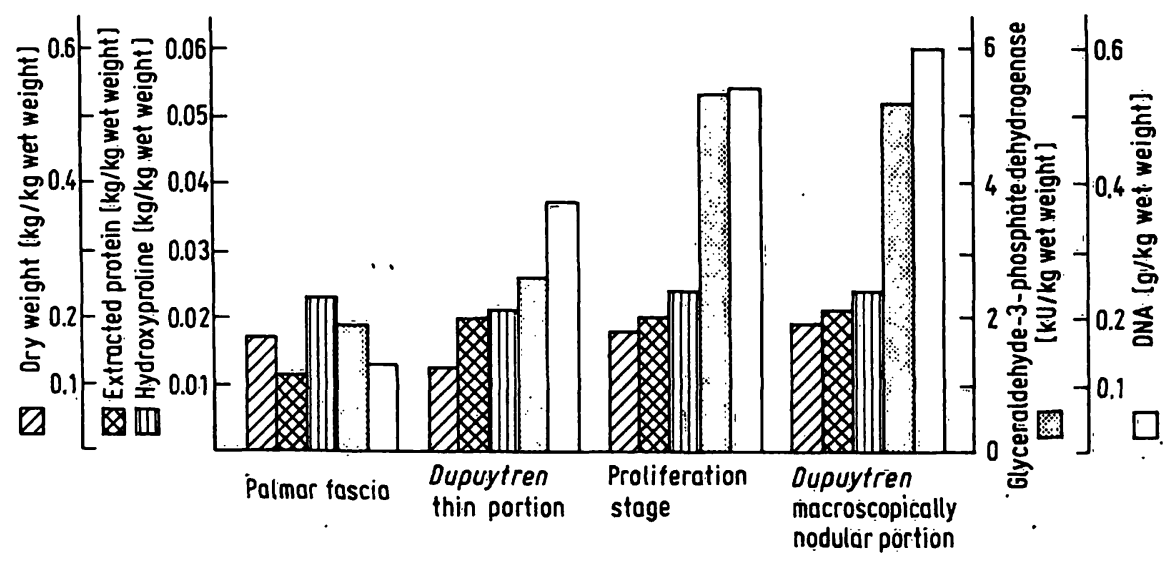

Fig. 1. Comparișon of dry weight, extracted protein, hydroxyproline, deoxyribonucleic acid contents and glyceraldehyde-3-phosphate dehydrogenase activity in fresh specimens from palmar fascia and Dupuytrë̆'s disease. 


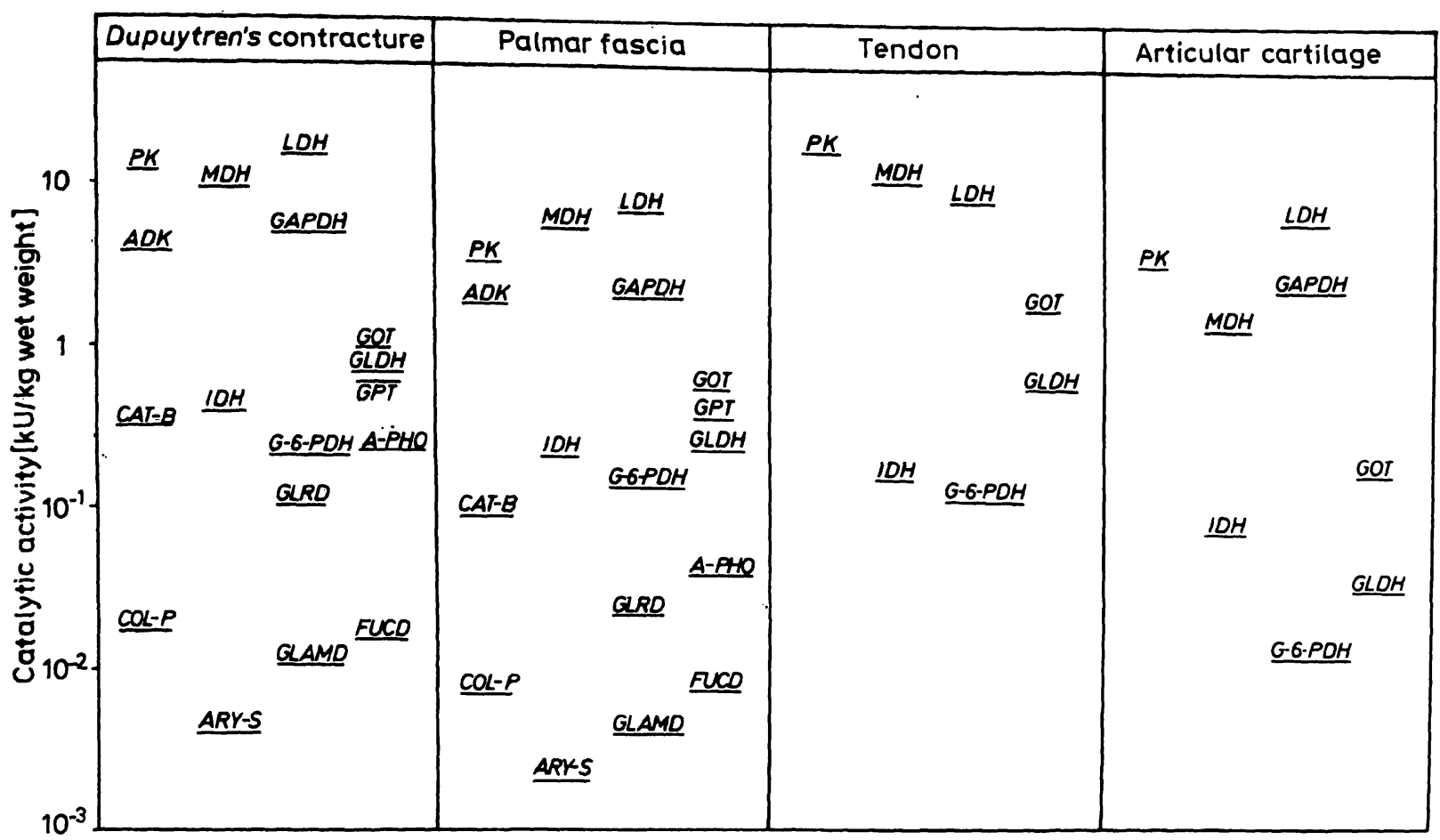

Fig. 2. Enzyme activity distribution patterns from Dupuytren contracture and human palmar fascia in comparison to human tendon and articular cartilage (11). Logarithmic scale. Activity in $\mathrm{kU} / \mathrm{kg}$ wet weight.

Abbreviations: LDH: Lactate dehydrogenase MDH: Malate dehydrogenase GAPDH: Glyceraldehyde-3-phosphate dehydrogenase PK: Pyruvate kinase IDH: Isocitrate dehydrogenase ADK: Adenylate kinase ARS: Arylsulfatase CAT-B: Cathep$\sin$ B 1 A-PHO: Acid phosphatase GLAMD: $\alpha$-N-Acetyl-glucosaminidase COL-P: Collagen peptidase FUCD: $\alpha$ - $L$-Fucosidase GOT: Glutamate-oxalacetate transaminase GPT: Glutamate-pyruvate transaminase GLRD: $\beta$-Glucuronidase G-6-PDH: Glucose-6-phosphate dehydrogenase PGK: 3-Phosphoglycerate kinase GLDH: Glutamate dchydrogenase The line under each abbreviation refers to the enzyme activity (ordinate).

Tab. 2A. Enzyme activities in U/kg wet weight of palmar fascia and of Dupuytren's contracture and subgroups.

\begin{tabular}{|c|c|c|c|c|c|c|c|c|c|c|c|c|}
\hline & \multicolumn{3}{|c|}{ Palmar fascia } & \multicolumn{3}{|c|}{$\begin{array}{l}\text { Nodular portion } \\
\text { Dupuytren's contracture }\end{array}$} & \multicolumn{3}{|c|}{$\begin{array}{l}\text { Thin portion } \\
\text { Dupuytren's contracture }\end{array}$} & \multicolumn{3}{|c|}{ Proliferating stage } \\
\hline & $\mathbf{n}$ & $\begin{array}{l}\bar{x} \\
(k U / k g\end{array}$ & $\begin{array}{l}s_{\bar{x}} \\
\text { wet weight) }\end{array}$ & n & $\begin{array}{l}\bar{x} \\
(\mathrm{kU} / \mathrm{kg})\end{array}$ & $\begin{array}{l}s_{\bar{x}} \\
\text { wet weight) }\end{array}$ & $\mathrm{n}$ & $\begin{array}{l}\bar{x} \\
(\mathrm{kU} / \mathrm{kg}\end{array}$ & $\begin{array}{l}s_{\bar{x}} \\
\text { wet weight }\end{array}$ & $\mathrm{n}$ & $\begin{array}{l}\bar{x} \\
(\mathrm{kU} / \mathrm{kg}\end{array}$ & $\begin{array}{l}s_{\bar{x}} \\
\text { wet weigh }\end{array}$ \\
\hline $\begin{array}{l}\text { Glycerinaldehyde-3- } \\
\text { phosphate dehy drogenase }\end{array}$ & 12 & $1.91 \pm$ & 0.15 & 28 & 4.90 & \pm 0.54 & 14 & 2.54 & \pm 0.26 & 12 & $4.59 \pm$ & \pm 0.88 \\
\hline Adenylate kinase & 13 & $1.80 \pm$ & 0.24 & 30 & 3.83 & \pm 0.48 & 14 & 1.25 & \pm 0.23 & 12 & 3.06 & \pm 0.45 \\
\hline Pyruvate kinase & 13 & $3.22 \pm$ & 0.39 & 29 & 11.6 & \pm 1.27 & 15 & 3.99 & \pm 0.58 & 12 & 10.5 & \pm 1.5 \\
\hline Isocitrate dehydrogenase & 12 & $0.20 \pm$ & 0.041 & 24 & 0.38 & \pm 0.039 & 10 & 0.21 & \pm 0.039 & 10 & $0.38=$ & \pm 0.059 \\
\hline Malate dehydrogenase & 13 & $5.22 \pm$ & 0.56 & 26 & 9.23 & \pm 0.95 & 9 & 6.10 & \pm 0.52 & 10 & 7.74 & \pm 1.05 \\
\hline Lactate dehydrogenase & 12 & $6.49 \pm$ & 0.85 & 31 & 14.6 & \pm 1.88 & 14 & 4.79 & \pm 0.95 & 12 & $12.8=$ & \pm 1.69 \\
\hline $\begin{array}{l}\text { Glucose-6-phosphate } \\
\text { dehydrogenase }\end{array}$ & 11 & $0.13 \pm$ & $=0.032$ & 23 & 0.20 & \pm 0.037 & 11 & 0.11 & \pm 0.021 & 11 & $0.17 \pm$ & \pm 0.041 \\
\hline $\begin{array}{l}\text { Glutamate-pyruvate } \\
\text { transaminase }\end{array}$ & 12 & $0.35 \pm$ & 0.05 & 22 & 0.60 & \pm 0.12 & 9 & 0.45 & \pm 0.12 & 10 & & \pm 0.053 \\
\hline $\begin{array}{l}\text { Glutamate-oxalacetate } \\
\text { transaminase }\end{array}$ & 11 & $0.53 \pm$ & $=0.078$ & 23 & 0.93 & \pm 0.13 & 9 & 0.64 & \pm 0.08 & 9 & 0.87 & \pm 0.12 \\
\hline Glutamate dehydrogenase & 11 & $\begin{array}{l}0.22 \pm \\
(\mathrm{U} / \mathrm{kg} \mathrm{w}\end{array}$ & 0.02 & 22 & $\begin{array}{r}0.66 \\
\text { (U/kg w }\end{array}$ & $\begin{array}{l} \pm 0.060 \\
\text { vet weight) }\end{array}$ & 10 & $\begin{array}{r}0.65 \\
\text { (U/kg w }\end{array}$ & $\begin{array}{l} \pm 0.1 \\
\text { wet weight) }\end{array}$ & 10 & $\begin{array}{r}0.72= \\
(\mathrm{U} / \mathrm{kg} \mathrm{w}\end{array}$ & $\begin{array}{l} \pm 0.092 \\
\text { weight) }\end{array}$ \\
\hline Collagen peptidase & 13 & $7.0 \pm$ & 1.94 & 19 & 17.1 & \pm 3.21 & 5 & 3.1 & \pm 1.34 & 7 & 14.7 & \pm 4.54 \\
\hline Cathepsin B 1 & 4 & $87.1 \pm$ & \pm 22 & 17 & 325 & \pm 37 & 15 & 110 & \pm 19.6 & 7 & $381=$ & \pm 47.3 \\
\hline Arylsulfatase & 9 & 2.0 & \pm 1.0 & 33 & 3.9 & \pm 0.52 & 14 & 2.1 & \pm 0.27 & 12 & 2.7 & \pm 0.58 \\
\hline$\alpha-L$-Fucosidase & 15 & 7.2 & \pm 1.86 & 32 & 15.0 & \pm 2.83 & 15 & 5.1 & \pm 0.77 & 11 & 9.7 & \pm 1.51 \\
\hline$\beta$-Glucuronidase & 15 & $21.6 \pm$ & \pm 2.84 & 35 & 102 & \pm 9.3 & 17 & 54.6 & \pm 5.58 & 12 & 99.0 & \pm 12.1 \\
\hline $\begin{array}{l}\alpha \cdot \mathrm{N} \text {-Ace tyl- } \\
\text { glucosaminidase }\end{array}$ & 14 & $3.9 \pm$ & \pm 1.1 & 35 & 10.3 & \pm 1.01 & 17 & 4.1 & \pm 0.73 & 12 & 12.1 & \pm 2.02 \\
\hline Acid phosphatase & 15 . & $37.3 \pm$ & $\pm \quad 3.9$ & 35 & 222 & \pm 37 & 17 & 49 & \pm 9.22 & 12 & 186 & \pm 39.8 \\
\hline
\end{tabular}


Tab. 2B. Lcvels of significance of enzyme activities per kg wet weight between palmar fascia, Dupuytren's contracture and subgroups.

\begin{tabular}{|c|c|c|c|c|c|c|}
\hline & & $\begin{array}{l}\text { Palmar } \\
\text { fascia }\end{array}$ & $\begin{array}{l}\text { Nodular } \\
\text { portions } \\
\text { Dupuytren's } \\
\text { contracture }\end{array}$ & $\begin{array}{l}\text { Thin } \\
\text { portion } \\
\text { Dupuytren's } \\
\text { contracture }\end{array}$ & $\begin{array}{l}\text { Proliferating } \\
\text { stage }\end{array}$ & \\
\hline & & p & $\mathbf{p}$ & $\mathbf{p}$ & p & \\
\hline \multirow[t]{7}{*}{ Palmar fascia } & & & 0.014 & 0.104 & 0.156 & Collagen peptidase \\
\hline & & & 0.001 & 0.461 & 0.0001 & Cathepsin B 1 \\
\hline & & & 0.108 & 0.981 & 0.532 & Arylsulfatase \\
\hline & & & 0.02 & 0.185 & 0.247 & $\alpha$ - $L$-Fucosidase \\
\hline & & & 0.0001 & 0.0001 & 0.0001 & $\beta$-Glucuronidase \\
\hline & & & 0.0001 & 0.866 & 0,002 & $\begin{array}{l}\alpha-\mathrm{N} \text {-Acetyl- } \\
\text { glucosaminidase }\end{array}$ \\
\hline & & & 0.0001 & 0.255 & 0.003 & Acid phosphatase \\
\hline \multirow{10}{*}{$\begin{array}{l}\text { Nodular portion } \\
\text { Dupuytren's } \\
\text { contracture }\end{array}$} & $\begin{array}{l}\text { Glyceraldehyde-3-phosphate } \\
\text { dehydrogenase }\end{array}$ & 0.000 & & 0.001 & 0.676 & Collagen peptidase \\
\hline & Adenylate kinase & 0.02 & & 0.0001 & 0.363 & Cathepsin B 1 \\
\hline & Pyruvate kinase & 0.000 & & 0.01 & 0.110 & Arylsulfatase \\
\hline & Isocitrate dehydrogenase & 0.001 & & 0.003 & 0.117 & $\alpha-L$-Fucosidase \\
\hline & Malate dehydrogenase & 0.001 & & 0.001 & 0.825 & $\beta$-Glucuronidase \\
\hline & Lactate dehydrogenase & 0.000 & & 0.0001 & 0.423 & $\begin{array}{l}\alpha-\mathrm{N}-\text { Acetyl- } \\
\text { glucosaminidase }\end{array}$ \\
\hline & $\begin{array}{l}\text { Glucose-6-phosphate } \\
\text { dehydrogenase }\end{array}$ & 0.23 & & 0.0001 & 0.511 & Acid phosphatase \\
\hline & Glutamate-pyruvate transaminase & 0.11 & & & & \\
\hline & $\begin{array}{l}\text { Glutamate-oxalacetate } \\
\text { transaminase }\end{array}$ & 0.05 & & & & \\
\hline & Glutamate dehydrogenase & 0.000 & & & & \\
\hline \multirow{10}{*}{$\begin{array}{l}\text { Thin portion } \\
\text { Dupuytren's } \\
\text { contracture }\end{array}$} & $\begin{array}{l}\text { Glyceraldehyde-3-phosphate } \\
\text { dehydrogenase }\end{array}$ & 0.05 & 0.000 & & 0.041 & Collagen peptidase \\
\hline & Adenylate kinase & 0.11 & 0.000 & & 0.001 & Cathepsin B 1 \\
\hline & Pyruvate kinase & 0.12 & 0.000 & & 0.295 & Arylsulfatase \\
\hline & Isocitrate dehydrogenase & 0.95 & 0.01 & & 0.022 & $\alpha-L$-Fucosidase \\
\hline & Malate dehydrogenase & 0.56 & 0.002 & & 0.004 & $\beta$-Glucuronidase \\
\hline & Lactate dehydrogenase & 0.36 & 0.000 & & 0.002 & $\begin{array}{l}\alpha-\mathrm{N} \text {-Acetyl- } \\
\text { glucosaminidase }\end{array}$ \\
\hline & $\begin{array}{l}\text { Glucose-6-phosphate } \\
\text { dehydrogenase }\end{array}$ & 0.62 & 0.007 & & 0.006 & Acid phosphatase \\
\hline & Glutamate-pyruvate transaminase & 0.75 & 0.32 & & & \\
\hline & $\begin{array}{l}\text { Glutamate-oxalacetate } \\
\text { transaminase }\end{array}$ & 0.31 & 0.28 & & & \\
\hline & Glutamate dehydrogenase & 0.001 & 0.93 & & & \\
\hline \multirow[t]{10}{*}{ Proliferating } & $\begin{array}{l}\text { Glyceraldehyde-3-phosphate } \\
\text { dehydrogenase }\end{array}$ & 0.002 & 0.90 & 0.008 & & \\
\hline & Adenylate kinase & 0.03 & 0.43 & 0.003 & & \\
\hline & Pyruvate kinase & 0.000 & 0.66 & 0.001 & & \\
\hline & Isocitrate dehydrogenase & 0.04 & 0.80 & 0.03 & & \\
\hline & Malate dehydrogenase & 0.06 & 0.34 & 0.1 & & \\
\hline & Lactate dehydrogenase & 0.002 & 0.58 & 0.001 & & \\
\hline & $\begin{array}{l}\text { Glucose-6-phosphate } \\
\text { dehydrogenase }\end{array}$ & 0.49 & $0.6^{\circ}$ & 0.24 & & \\
\hline & Glutamate-pyruvate transaminase & 0.69 & 0.07 & 0.57 & & \\
\hline & $\begin{array}{l}\text { Glutamate-oxalacetate } \\
\text { transaminasc }\end{array}$ & 0.03 & 0.59 & 0.13 & $\cdot$ & \\
\hline & Glutamate dehydrogenase & 0.000 & 0.610 & 0.62 & & $\cdots$ \\
\hline
\end{tabular}


phosphate dehydrogenase are much lower and are in the range of the lower limit of analytical accuracy. The enzyme patterns resemble those of other connective tissues such as tendon or cartilage (fig. 2; (29), (30)). The activities of lysosomal enzymes are two to three orders of magnitude lower than the activities of main metabolic pathway enzymes. In palmar fascia and Dupuytren's contracture the activities of cathepsin B 1 and acid phosphatase exceed those of other lysosomal enzymes. The absolute activities calculated on the wet weight basis of the specimens are two to three times higher in Dupuytren's contracture than in palmar fascia. The thin portion of Dupuytren's contracture is significantly different from Dupuytren's contracture and from palmar fascia with respect to the enzyme activities, whereas the proliferating stage does not differ from the total Dupuytren's contracture group but differs from the palmar fascia group. Calculated on the basis of DNA, the absolute activities for both lysosomal and main metabolic pathway enzymes are somewhat higher in palmar fascia than in Dupuytren's contracture (tab. 3). Enzyme activities based on the glyceraldehyde-3-phosphate dehydrogenase activity show no statistically significant differences in specimens from Dupuytren's contracture or palmar fascia (tab. 4, fig. 3).

The absolute activities as well as the enzyme activity distribution patterns of fibroblasts from palmar fascia and Dupuytren's contracture are identical. In particular, the activities of lysosomal enzymes do not differ significantly between both strains of cultured fibroblasts. The activity distribution patterns (based on the activity of glyceraldehyde-3-phosphate dehydrogenase) of main metabolic pathway enzymes from fibroblasts and the respective tissue specimens from palmar fascia and Dupuytren's contracture (fig. 3) differ only slightly. While adenylate-kinase and pyruvate-kinase are lower, lactate dehydrogenase and glucose-6-phosphate dehydrogenase show a higher activity in fibroblasts than the corresponding tissue specimens (statistical significance see table 3). Due to the small number of samples of palmar fascia cell strains tested, the significance of these differences are less than those for Dupuytren's contracture tissue specimens and Dupuytren's contracture cell cultures. However, lysosomal enzyme activity patterns are different for tissue specimens and cultured fibroblasts. In general, the activities of these enzymes are higher in relation to the main metabolic pathway enzymes in tissue specimens than in the respective cultured fibroblasts. This is especially true for $\beta$-glucuronidase and $\alpha$-N-acetyl-glucosaminidase (fig. 3).

A great difference in overall activities could be shown by comparing tissue enzymes with cultured fibroblast enzymes on the basis of the DNA content. Enzyme activities per $\mathrm{g}$ DNA are 10 to 50 times higher in fibro-

Tab. 3. Enzyme activities in cultured fibroblasts from Dupuytren's contracture and palmar fascia. U/U glyceraldehyde-3-phosphate dehydrogenase. Significance level of differences between both fibroblast groups (A); between fibroblasts from Dupuytren's contracture and Dupuytren's contracture tissue (B); and fibroblasts from palmar fascia and palmar fascia tissue (C) (see table 2A).

\begin{tabular}{|c|c|c|c|c|c|c|c|}
\hline & \multicolumn{2}{|c|}{$\begin{array}{l}\text { Fibroblasts } \\
\text { Palmar fascia }\end{array}$} & \multicolumn{2}{|c|}{$\begin{array}{l}\text { Fibroblasts } \\
\text { Dupuytren's contracture }\end{array}$} & \multicolumn{3}{|c|}{ Significance level } \\
\hline & $\mathrm{n}$ & $\begin{array}{l}\overline{\mathbf{x}} \pm s \overline{\mathbf{x}} \\
\text { (U/U } \\
\text { Glyceraldehyde-3- } \\
\text { phosphate } \\
\text { dehydrogenase) }\end{array}$ & $\mathrm{n}$ & $\begin{array}{l}\overline{\mathrm{x}} \pm s \overline{\mathrm{x}} \\
\text { (U/U } \\
\text { Glyceraldehyde-3- } \\
\text { phosphate } \\
\text { dehydrogenase) }\end{array}$ & $\mathbf{A}$ & B & $\mathrm{C}$ \\
\hline Adenylate kinase & 5 & $0.29 \pm 0.05$ & 27 & $0.36 \pm 0.03$ & n.s & $<0.0001$ & $<0.001$ \\
\hline Pyruvate kinase & 6 & $0.99 \pm 0.33$ & 31 & $0.98 \pm 0.12$ & n.s & $<0.0001$ & $<0.02$ \\
\hline 3-Phosphoglycerate kinase & 4 & $1.49 \pm 0.09$ & 27 & $1.84 \pm 0.14$ & n.s & - & - \\
\hline Lactate dehydrogenase & 5 & $4.29 \pm 0.29$ & 29 & $4.05 \pm 0.2$ & $\mathrm{n} . \mathrm{s}$ & $<0.001$ & $<0.2$ \\
\hline \multirow{2}{*}{$\begin{array}{l}\text { Glucose-6-phosphate } \\
\text { dehydrogenase }\end{array}$} & 5 & $0.16 \pm 0.03$ & 22 & $0.13 \pm 0.02$ & n.s & $<0.0001$ & $<0.02$ \\
\hline & & $\begin{array}{l}\text { (mU/U } \\
\text { Glyceraldehyde-3- } \\
\text { phosphate } \\
\text { dehydrogenase) }\end{array}$ & & $\begin{array}{l}\text { (mU/U } \\
\text { Glyceraldehyde-3- } \\
\text { phosphate } \\
\text { dehydrogenase }\end{array}$ & . & & \\
\hline Collagen peptidase & 5 & $3.23 \pm 0.38$ & 27 & $3.63 \pm 0.22$ & n.s & n.s. & n.s. \\
\hline Arylsulfatase & 4 & $1.36 \pm 0.85$ & 24 & $0.85 \pm 0.05$ & 0.02 & $<0.02$ & n.s. \\
\hline $\beta$-Glucuronidase & 5 & $3.71 \pm 1.66$ & 27 & $4.09 \pm 0.31$ & n.s & $<0.0001$ & $<0.01$ \\
\hline$\alpha$-N-Acetyl-glucosaminidase & 5 & $0.24 \pm 0.05$ & 25 & $0.26 \pm 0.04$ & n.s & $<0.0001$ & $<0.002$ \\
\hline Acid phosphatase & 5 & $15.2 \pm 2.72$ & 25 & $13.6 \pm 1.3$ & n.s & $<0.01$ & $<0.2$ \\
\hline
\end{tabular}


Tab. 4. Comparison of enzyme activities calculated on the DNA basis in specimens from Dupuytren's contracture and normal palmar fascia.

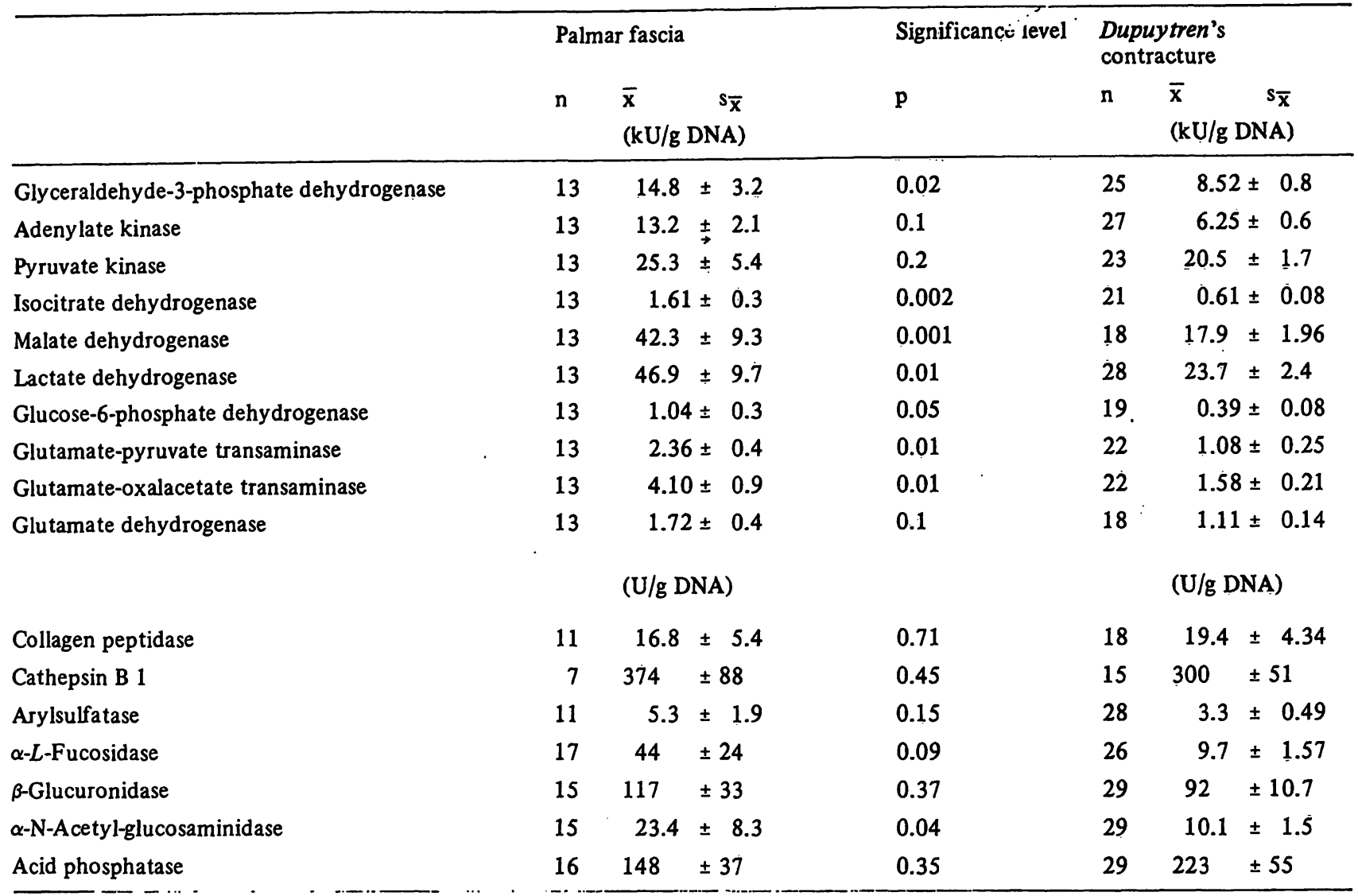

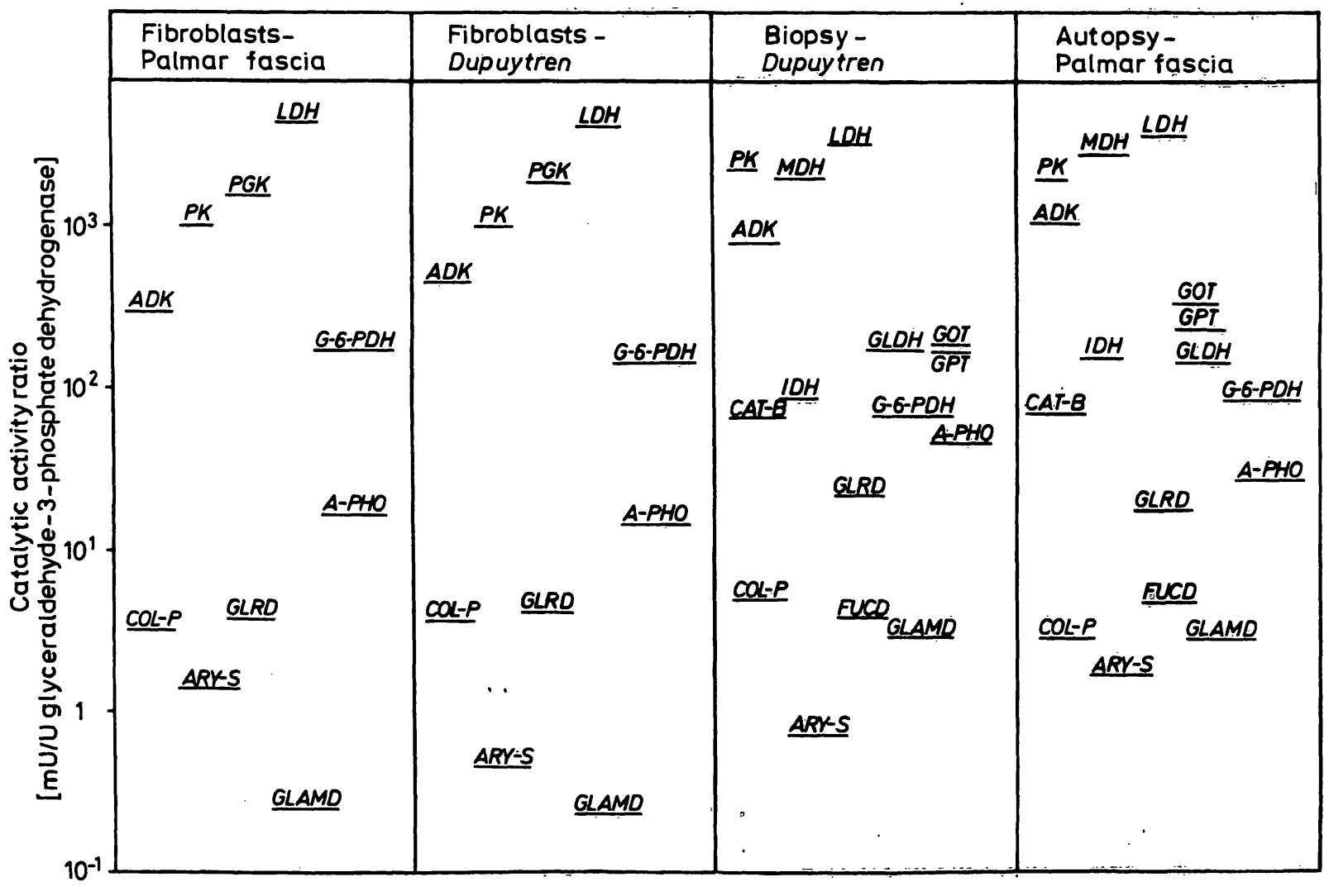

Fig. 3. Comparison of enzyme activity distribution patterns from cultured fibroblasts (Dupuytren's contracture, palmar fascia) with the respective patterns of tissue specimens on the basis of glyceraldehydc-3-phosphate dehydrogenase activity, Logarithmic scale. Explanations see fig. 2. 
blasts depending on the duration of the growth period and/or the density of fibroblasts in the cell layer (fig. 4 , 5). This applies to Dupuytren's contracture and Dupuytrens's contracture fibroblasts, and to palmar fascia . . and palmar fascia fibroblasts. During the course of cell growth, enzyme activities and protein content of the cells decrease while the DNA content remains almost unchanged (fig. 5). Enzyme activities closely correlate with the protein content of the cells (for lactate dehydrogenase/protein $r=0.91$ for $n=24$ ).

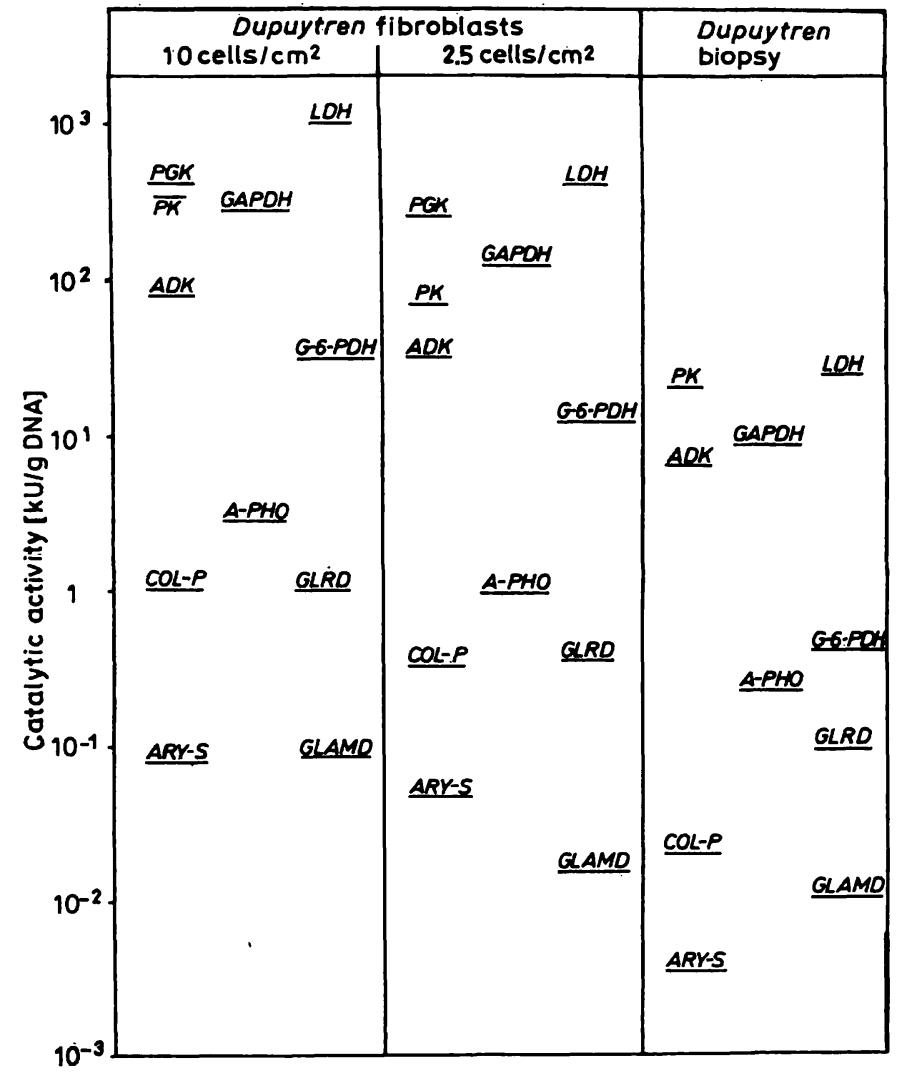

Fig. 4. Enzyme activity distribution patterns on the basis of the DNA content in cultured fibroblasts of different cell density in comparison to the respective tissue specimens. Logarithmic scale. Explanations see fig. 2.

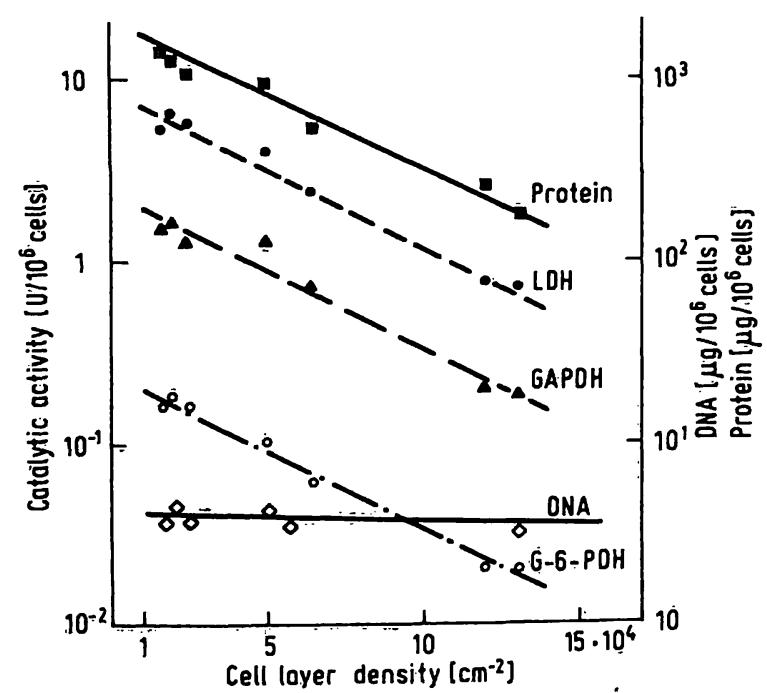

Fig. 5. Enzyme activities, extractable protein and DNA contents of cultured fibroblasts in dependence of the cell layer density. Activity in U/10 $10^{6}$ cells, protein and DNA in $\mu \mathrm{g} / 10^{6}$ cells. Logarithmic scale. Abbreviations see fig. 2.

\section{Discussion}

Since the tissue samples were homogeneous and the blood impurities negligible $(0.01 \%)$, the possibility of falsification of the enzyme patterns by enzymes from other sources was excluded. However, due to the difficulties of equally disrupting strong connective tissue portions, the scatter of the results within the individual groups is relatively high. A mean of $90 \%$ of the total enzyme activities was extracted by the method applied in this study. On the other hand, fibroblast extraction leads to more precise results with smaller deviation from the mean. The latter can be achieved only when fibroblasts of the same cell density in culture are taken for extraction. The methodological scatter of the results partly explains the poor significance of differences between the groups for those enzymes with low activities in the tissues. For interpretation of the data on enzyme activities, the metabolic capacity of the respective tissue as well as that of the individual cell must be taken into consideration. The basis for a comparative interpretation should be first the wet weight, then the DNA content or the cell number. Extracted protein, however, did not prove to be a suitable reference in the tissues under investigation. The missing correlation between values for extracted protein and DNA content (fig. 1) shows that, in addition to the metabolically active enzyme proteins, other proteins such as neutral salt-soluble collagen are extracted under the experimental conditions applied in this study. Due to the constant correlation of enzyme activities in different tissues, extractable enzyme proteins offer a further possibility of a reference system (31). For instance, glyceraldehyde-3-phosphate dehydrogenase as a key enzyme of glycolysis (32) could be used as reference for the comparison and interpretation of enzyme patterns of the specimen groups under discussion.

The data on the enzyme activities in palmar fascia and Dupuytren's contracture allow the conclusion that the higher metabolic activity of Dupuytren's contracture does not depend on changes in the enzymatic activities within the individual cell, but rather on the larger number of cells present in the diseased portions of the tissue, as seen in the morphological examination of the Dupuytren's contracture samples (3). These findings are in agreement with the higher DNA content of the Dupuytren's contracture samples compared with palmar fascia specimens. However, the enzyme activities based on the DNA content are lower in Dupuytren's contracture than in palmar fascia. These differences might be explained by a higher DNA content per cell in proliferating cells of Dupuytren's contracture compared to the nonproliferating cells in palmar fascia. On the other hand, preliminary experiments on main metabolic pathway enzyme activities in growing fibroblasts (fig: 5 ) showed a decrease in enzyme activity and protein content per cell of cultured fibroblasts with increasing age and density of cells. If cell density is the regulating factor 
for the activity of cell enzymes, the difference in enzyme activity per DNA (or cell) could be attributed to the isolated localisation of cells in palmar fascia in contrast to the proliferating cell clusters in Dupuytren's contracture (see below).

Although histologically Dupuytren's contracture exhibits tissue breakdown alongside tissue regeneration, the activities of lysosomal peptidases (cathepsin B 1, collagen peptidase) involved in collagen breakdown (33, $34,25)$, the carbohydrases and the acid phosphatase do not significantly differ between palmar fascia and Dupuytren's contracture on the tissue DNA basis. This means that the elevated metabolic turnover of extracellular compounds is provided by an increased cell number in Dupuytren's contracture.

The data of Hoopes et al. (12) differ considerably from the results of this study. Based on the DNA content, the authors reported an increase in enzyme activities in specimens of Dupuytren's contracture which varied between 1 and 10 times from enzyme to enzyme. However, the methods applied for enzyme activity determinations were different. Hoopes et al. incubated tissue slices instead of testing tissue extracts which means that enzymes or substrates have to penetrate extracellular matrix and fibres prior to enzymatic action on the substrates. This extracellular compartment is assumed to be a stronger barrier for both enzymes and substrates in the case of the intact palmar fascia than in the pathological structure of Dupuytren's contracture. In addition, the penetration rates of the different substrates or enzyme proteins may vary, thus causing different elevation rates of individual enzymes as reported by the authors. Calculating the activities determined by Hoopes et al. on the basis of glyceraldehyde-3-phosphate dehydrogenase, the differences in enzyme activities are in the range of 1-2 fold, depending on the activity of glyceraldehyde-3-phosphate dehydrogenase given by the assay method. Moreover, tissue slices contain more or less intact cells, subcellular microstructures, and substrates in various concentrations, providing metabolic reaction sequences which may interfere with the specific enzyme reactions to be determined. These methodological differences apply also to the data published by Hoopes et al. on enzyme activities in hyperytrophic scars and keloids (36). The difficulties involved in the techniques used by the authors are evident by the fact that, in normal dermis, no measurable glyceraldehyde-3phosphate dehydrogenase activity was detected; this seems very unlikely in view of the high activities of other enzymes of the Embden-Meyerhof pathway in the examined specimens. Although the data of Hoopes et al. are not comparable to the results given in this paper, they do demonstrate a considerable metabolic activity of palmar fascia and Dupuytren.

Studies on the synthesis of collagen and acid glycosaminoglycans in cultured fibroblasts have shown an enhanced $\left[{ }^{3} \mathrm{H}\right]$ hydroxyproline and $\left[{ }^{35} \mathrm{~S}\right]$ sulfate incorporation in cells cultured from Dupuytren's contracture biopsies compared to palmar fascia fibroblasts (26). Corresponding differences in the determined enzyme activities are missing in the respective fibroblasts (fig. 3). However, there are some distinct differences between enzyme activities in fibroblasts and the respective tissue specimens from which fibroblasts were derived (fig. 3, tab. 3), with respect to the overall activity and the relationship of the activities of lysosomal enzymes to those of main metabolic pathway enzymes. These differences very probably have a methodological basis. In the case of the tissue specimens, the extraction procedure includes the extracellular compartment, and this may contain varying relative quantities of individual secreted lysosomal enzyme proteins. However, the fibroblasts were isolated from the surrounding medium prior to the extraction. In this way the extracellular portion of the lysosomal enzyme activities was removed before activity determinations. Enzyme activity determinations in isolated cells offer the opportunity to distinguish between intracellular activity of lysosomal enzymes and the activity of the secreted enzyme proteins. When setting up cell culture experiments along with enzyme activity assays in tissue specimens, it should be possible to answer the question whether enzyme activities derive from the specific cells of the respective tissue or originate from other sources such as granulocytes or macrophages. No final explanation can be offered as to the differences in enzyme activity per $\mathrm{g}$ DNA between tissue and the respective cultured fibroblasts (fig. 4). Experimental errors in DNA determination can be excluded since the respective data from tissue and cultured fibroblasts concur with those of the literature $(12,37)$. The data on the dependence of enzyme activity upon cell density in cultured fibroblasts suggest a mechanism by which the enzyme activity is regulated by extracellular factors, such as cell to cell interaction or the state of extracellular matrix. Future studies must be performed to reveal more detailed information on this matter and prove the possibility of establishing similar data in in vivo systems of proliferating cells. For the present, it must be emphasized that work on the metabolism of fibroblasts, using cultured cells, should take into consideration the comparability of the state of cell growth and the density of the cells under investigation.

\section{Acknowledgements}

The authors are very indebted to Prof. Dr. med. Köhnlein and his colleagues from the Department to Plastic and Reconstruction Surgery, Hannover Medical School, for their assistance in collecting the specimens of Dupuytren's contracture and to the colleagues from the Department of Pathology (Prof. Dr. med. Georgii) for providing the autopsy specimens, especially to Dr. Schnaidt for preparing the slices and assistance in interpretation of the microscopical morphology. The authors express their gratitude to Dr. Törek, Department of Biometrics, Hannover Medical School for their valuable assistance in statistical evaluation of the experiments. 


\section{Refererces}

1. Plater, F. (1614), Obscrvationum in homines affectibus plerisque corpori ct animo functionum laesione, dolore, aliave molestia et vitio insensis libri tres, 2. Aufl. Basel (Neuauflagen 1630, 1641)

2. Dupuytren, G. (1832), Lecons orales de clinique chirurgicale faites a l'Hotel Dieu de Paris, G. Balliere, Vol. 1 (1832).

3. Mackenzie, D. H. (1979), The differential diagnosis of fibroblastic disorders. Blackwell scientific publications, Oxford and Edinburgh, p. 82-86.

4. Luck, J. V. (1959), J. Bone Jt. Surg. 41A, 635.

5. Tyrkkoe, J. \& Viljanto, J. (1975), Ann. Chir. Gynaegol. Fenn. 64, 288-291.

6. Tessari, L. \& Parini, L. (1958), Arch. Ortop. 72, 435-441.

7. Lagier, R. \& Exer, B. (1960), Virchow's Archiv 333, 68-80.

8. Carr, T. L. (1979), Hand 1, 50-55.

9. Viljanto, J., Scppaelac, P. O. \& Lethonen, A. (1971), Ann. Rheum. Dis. 30, 423-427.

10. Hunter, A. A., Ogdon, C. \& Norris, M. G. (1975), Brit. J. Plast. Surg. 28, 10-18.

11. Delbrück, A. (1962), Klin. Wochenschr. 40, 677-684.

12. Hoopes, J. E., Iabaley, M. E., Chi-Tsung Su, Wilgies, E. F. S. \& Im, M. J. C. (1977), J. Hand. Surg. 2, 62-65.

13. Webb, E. C. \& Morrow, P. F. W. (1959), Biochem. J. 73, 7-15.

14. Szasz, G. (1967), Clin. Chim. Acta 15, 275-282.

15. Weissmann, B., Rowin, G., Marshall, J. \& Friedrici, D. (1967), Biochemistry 6, 207-214.

16. Levy, G. A. \& McAllan, A. (1961), Biochem. J. 80, 435439.

17. Gries, G., Buresch, H. \& Strauch, L. (1970), Experientia 26, 31-33.

18. Barret, A. J. (1972), Anal. Biochem. 47, 280-293.
19. Lce, H. J., La Ruc, J. N. \& Wilson, J. B. (1971), Anal. Biochem. 41, 397-401.

20. DiPictro, D. L. \& Zengerle, F. S. (1967), J. Biol. Chem. 242, 3391-3396.

21. Weichselbaum, T. E. (1946), Amcr. J. Clin. Pathol. 10, 40.

22. Lowry, D. H., Rosenbrough, N. J., Furr, A. L. \& Randall, R. J. (1951), J. Biol. Chem. 193, 265-275.

23. Crosby, W. H. \& Furth, F. W. (1956), Blood 11, 380.

24. Burton, K. (1956), Biocliem. J. 62, 315.

25. Delbrück, A. \& Schröder, H. unpublished results.

26. Stegemann, H. (1958), Hoppe-Seyler's Z. Physiol. Chem. $311,41-45$.

27. Watthiaux, R. \& C. De Duve (1956), Biochem. J. 63, 606608.

28. Niehe, N. H., Statistical package social sciences Mc. Grawhill, New York, 2. ed. 1975.

29. Dclbrück, A. (1964), Enzy mol. Biol. Clin. 4, 84-106.

30. Patzschke, E. \& Delbrück, A. (1967), Enzymol. Biol. Clin. $8,421-450$.

31. Delbrück, A., Zebc, E. \& Bücher, Th. (1959), Biochem. Zschr. 331, 273-296.

33. Tappel, A. L. in Dingl, J. T. \& Fell, B. Ed. (1969), The lysosomes in biology and pathology, Vol. 2, pp. 207-244.

34. Stojan, B., Müller, W., Wurm, K. \& Tariverdian, M. (1973), Schwciz. Med. Wochenschr. 103, 337-341.

35. Lindner, J. (1972), Archiv Dermatol. Forsch. 244, 104-112.

36. Hoopes, J. E., Su, C. T. \& Im, M. J. C. (1971), Plast. Reconstr. Surg. 47, 132-137.

37. Leyva, A. jr. \& Kelley, W. N. (1974), Anal. Biochem. 62, 173-179.
Prof. Dr. med. A. Delbrück Abt. IV (Klinische Chemie) Zentrum für Laboratoriumsmedizin der Med. Hochschulc Hannover Zentrallabor im Krankenhaus Oststadt Podbiclskistraße 380 D-3000 Hannover 51 
